\title{
The Impact of Intelligent Science and Technology on Human Society: Appeals of Institutional System ${ }^{+}$
}

\author{
Kun Wu, Kaiyan Da * and Wenbao Ma \\ School of Humanities and Social Sciences, Xi'an Jiaotong University, Xi'an 710049, China; \\ wukun@mail.xjtu.edu.cn (K.W.); smiling-ma@163.com (W.M.) \\ * Correspondence: dky850731@stu.xjtu.edu.cn; Tel.: +86-1896-690-3388 \\ † The Fourth International Conference on Philosophy of Information, Berkeley, CA, USA, 2-6 June 2019. \\ Published: 15 May 2020
}

\begin{abstract}
As the degree of intelligence in social development increases, the future society will present new features. For example, the necessary labor time for humans will be greatly shortened. The direct result of this is the rapid growth of unemployed people. Many jobs in the future society will be replaced by intelligent machines, and a differentiation of new social stratification will emerge, bringing new social problems and new institutional appeals. The innovations of this article are: first, "the rapid growth of the unemployed people is a great progress of society" is the creative idea of this article, which is different from the views of many economists; second, this article envisions a differentiation of a new social stratification of the future society - the base stratum, the middle stratum, and the top stratum-and analyzes the social problems brought about by the differentiation of new social stratification; third, this article puts forward the institutional appeal of a shared society based on the principle of economic distribution of "social security + distribution according to labor", and proposes reasonable philosophical suggestions for the future development of humans.
\end{abstract}

Keywords: intelligence; unemployment; stratum; social system; principle of sharing

\section{Introduction}

As we enter the 21st century, and the degree of intelligence in social development increases, the future society will present new features. Different people have different opinions about the fast and increased changes. Some are optimistic, while others are pessimistic. In fact, as long as we make full preparations for the changes in advance, I am sure that we can calmly face the future without being afraid of anything. Based on this, how to reasonably evaluate the future development of intelligent science, how to actively face, research and develop intelligent science, how to reasonably and appropriately guide people to understand intelligent science and how to better design the systems of our science and technology, politics, economics, culture and education are the main topics of this paper.

\section{Viewpoint 1: The Reduction in Working Hours Shows Great Progress in Society}

Nowadays, many experts and philosophers, especially economists, hold the idea that the rapid of growth of unemployed people is a symbol of social unrest. They think that the higher the rate of the unemployment, the more unstable the society. However, this paper will offer a different opinion.

From human history, we can clearly see that the shorter the working hours, the more advanced the society is. Let us go back to primitive society. The lack of food forced men to go hunting animals and women to go collecting fruit. They had to work for a whole day or a whole week to bring something back for their family or tribe. Sometimes, if they were not lucky enough, they would bring nothing. Then, they invented some tools, such as stones, knives and arrows, which helped them get 
more foods and make their lives easier. Fire was another great invention. With these tools, they worked less hours. When they had enough food, they would choose not to go outside and stayed with their families instead. The direct result was the rapid growth of the social population. Roughly a thousand years later, the Industrial Revolution brought humans into a new age. They had more advanced tools called machines. People did not have to do the heavy and jobs with long hours. In some countries, the government regulated that the working hours of workers should be no more than eight hours per day, which was a great relief to human labor. When off work, people would have more time to entertain themselves, for example, by watching movies, chatting with friends, shopping in the mall and travelling the world. Some decades later, the invention of the computer has brought us into another great new age called the information age. With the rapid development and popularization of production automation, intelligent science and intelligent technology, not only people' s physical work, but also part of their mental work, may be replaced by machines and robots. In this way, it is inevitable that people will have a larger reduction in the labor time necessary to maintain their livelihood.

Do not worry. First, working hours have been steadily falling in most countries for the last 50 years. Second, fewer working hours does not necessarily mean lower total output or lower productivity. Third, as working hours decrease, workers focus more on work-life balance and how to spend their leisure time [1].

\section{Viewpoint 2: New Social Stratification Will Appear}

When a large number of intelligent machine systems and intelligent robots replace people's traditional labor industries, the basic work industries leave to humans can be roughly divided into three categories.

The first is the management, maintenance and guidance of intelligent machine systems and intelligent robots.

The second is the coordination and management of the relationship between robots and robots, people and robots, and people and people. These will be the main social service fields for various government agencies in the future. Of course, a lot of work in this field may also be replaced by robots.

The third is to engage in higher levels of creative research and manufacturing activities, such as creating new and improving old intelligent machine systems and intelligent robots, using new technological means to change or enhance people's own nature and capabilities, and developing human's own cultural entertainment.

The new social stratification is shown in Figure 1.

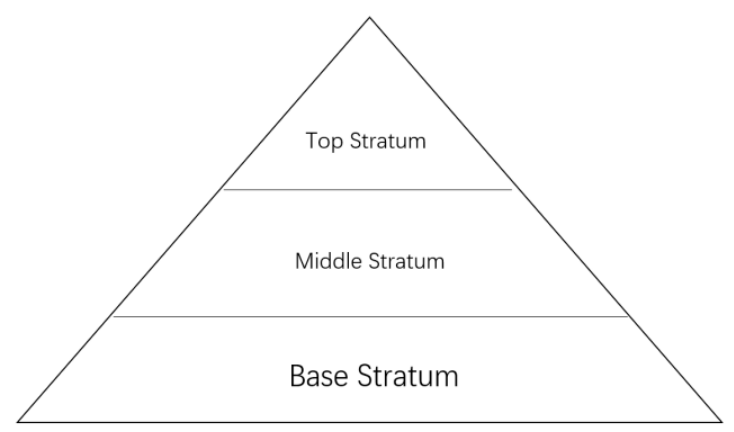

Figure 1. New Social Stratification.

\section{Appeals of Institutional System}

Talcott Parsons was the first to formulate a systematic theory of social systems. He defines a social system as a network of interactions between actors [2]. Based upon his theory, in order to properly solve the above social problems, to maintain and develop human society in a healthy and harmonious atmosphere, it is necessary to establish a highly developed new social system that adapts to the human-computer symbiosis world. 
Firstly, this new social system must adapt to a society in which social wealth is highly shared. It should effectively ensure that unemployed people at the bottom of society can also live a decent and rich life. This point should not be a problem in a highly developed and intelligent society, because a world of human-machine symbiosis must be a world in which social wealth is abundant. If the social wealth is not monopolized by a few people, there will be no problem at all in obtaining a relatively affluent life for the whole society.

Secondly, this new social system should try to make more people employed.

Thirdly, it is necessary to legislate relevant creative research and the management and use of corresponding intelligent products to prevent possible harm to humans. In this respect, the concept of robots harming humans and intelligent technology destroying humans that many people worry about is not purely talk [3].

Funding: This research was funded by National Social Science Fund, grant number 18ZDA027.

Conflicts of Interest: The authors declare no conflict of interest.

\section{References}

1. Dolton, P. Working Hours: Past, Present, and Future. IZA World Labor 2017, doi:10.15185/izawol.406.

2. Parson, T. The Social System; Routledge: London, UK, 2018.

3. Wu, K.; Da, K.Y. The Comprehensive Human Essence and the New Evolution of Human Beings. Academics 2019, 8, 185-194.

(C) 2020 by the authors. Licensee MDPI, Basel, Switzerland. This article is an open access article distributed under the terms and conditions of the Creative Commons Attribution (CC BY) license (http://creativecommons.org/licenses/by/4.0/). 